\title{
传统主食制造产业发展现状与对策研究
}

\author{
朱蓓薇 ${ }^{1,2}$, 孙娜 $^{1,2}$, 李冬梅 ${ }^{1,2}$, 谭斌 ${ }^{3}$ \\ (1. 大连工业大学食品学院, 辽宁大连 116034；2. 辽宁海洋食品精深加工关键技术省部共建协同创新中心， \\ 辽宁大连 116034；3. 国家粮食和物资储备局科学研究院，北京 100037）
}

摘要: 主食事关国计民生, 在我国居民膳食结构中具有基础性和框架性的地位, 虽然我国主食制造产业发展势态良好、产业 集聚趋势明显, 但工业化和标准化生产的水平仍有待进一步提升。本文梳理了我国传统主食制造产业的战略背景和发展现状, 凝练了产业发展面临的问题。依据国家整体战略布局和行业长期规划, 提出了相关对策建议: 抓牢源头, 选育适宜传统主食 加工的优质专用品种; 调整产品结构, 推进传统主食制造产业改造升级; 发展全谷物食品, 推动传统主食加工向健康谷物创 新升级; 加强技术与设备研发, 促进传统主食制造产业与智能制造深度融合; 完善传统主食标准化体系, 促进传统主食制造 产业走向规范化和科学化。

关键词：传统主食；制造产业；主食产业化；发展现状

中图分类号: TS2 文献标识码: A

\section{Traditional Staple Food Manufacturing Industry in China: Development Status and Countermeasures}

\author{
Zhu Beiwei ${ }^{1,2}$, Sun Na ${ }^{1,2}$, Li Dongmei ${ }^{1,2}$, Tan Bin ${ }^{3}$
}

(1. School of Food Science and Technology, Dalian Polytechnic University, Dalian 116034, Liaoning, China; 2. Collaborative Innovation Center of Provincial and Ministerial Co-construction for Marine Food Deep Processing, Dalian 116034, Liaoning, China; 3. Academy of National Food and Strategic Reserves Administration, Beijing 100037, China)

\begin{abstract}
Staple food is crucial to the national economy and people's livelihood and it occupies a fundamental and framework status in people's dietary patterns in China. Although the staple food manufacturing industry develops well in China and has an obvious trend of industrial agglomeration, the level of industrialization and standardized production of the industry needs further improvement. This study analyzes the strategic background and development status of the traditional staple food manufacturing industry in China and summarizes the challenges faced by the industry. Based on the national development strategy and long-term planning of the industry, we propose several suggestions, including breeding high-quality varieties that are suitable for traditional staple food processing; adjusting the product structure as well as promoting the transformation and upgrading of the traditional staple food manufacturing industry; developing whole grain foods and upgrading the traditional staple food processing toward healthy grain; strengthening the research and development of technologies and equipment as well as promoting the deep integration between the traditional staple food manufacturing industry and intelligent manufacturing; and improving the standardization system to promote the industry to be standardized and scientific.
\end{abstract}

Keywords: traditional staple food; manufacturing industry; staple food industrialization; development status

收稿日期 : 2020-04-15; 修回日期 : 2020-05-25

通讯作者: 朱蓓薇, 大连工业大学食品学院教授, 中国工程院院士, 研究方向为食品资源与综合利用; E-mail: zhubeiwei@163.com 资助项目：中国工程院咨询项目“传统主食制造产业发展战略咨询研究” (2019-XY-25)

本刊网址 : www.engineering.org.cn/ch/journal/sscae 


\section{一、前言}

主食事关国计民生，在我国居民膳食结构中具 有基础性和框架性的地位。自古《黄帝内经・素问》 有 “五谷为养, 五畜为益, 五菜为充, 五果为助” 的记载, 体现了 “五谷为主、果蔬为辅” 的居民膳 食结构。《中国居民膳食指南（2016）》指出：主食 位于中国居民平衡膳食宝塔的第 1 层, 是膳食结构 的根基, 也是提供人体所需能量最重要的食物来源。 《粮食加工业发展规划（2011－2020 年)》将主食品 定义为: 供应居民一日三餐消费、满足人体基本能 量和营养摄入需求的主要食品。我国传统主食品主 要包括面制主食品和米制主食品两类, 如馒头、面 条、饺子、油条、包子、米饭、方便米饭、方便米 粉等。

为了推动传统主食制造产业的可持续发展, 2017 年, 《中共中央国务院关于深入推进农业供给 侧结构性改革 加快培育农业农村发展新动能的若 干意见》要求, 实施主食加工业提升行动, 积极推进 传统主食工业化、规模化生产; 《关于加快推进农业 供给侧结构性改革 大力发展粮食产业经济的意见》 在 “大力促进主食产业化” 方面作了具体部署, 提出 支持推进米面、玉米、杂粮及薯类主食制品的工业化 生产, 保护并挖掘传统主食产品, 增加花色品种。

随着时代的进步、人们生活节奏和城市化进程 的加快, 我国主食加工业发展迅速。在消费需求拉 动下, 工业化主食逐渐走上大众餐桌, 以稻米、小 麦、玉米、杂粮、薯类等为加工原料, 经过传统或 改良方式制造的主食制品不断进入市场。然而, 我 国主食加工业起步相对偏晚, 基础研究仍显薄弱, “卡脖子” 问题较为突出, 导致产业发展较为缓慢。 针对于此, 本文重点开展传统主食制造产业的发展 对策研究, 以期为传统主食制造产业转型升级、传 统主食科技创新能力提升提供理论参考。

\section{二、发展传统主食制造产业的宏观背景}

\section{（一）发展传统主食制造产业, 保障国家粮食安全}

近年来, 国家坚持将解决粮食安全问题作为首 要任务, 立足世情、国情、粮情, 进行了一系列重 大部署 [1], “确保国家粮食安全, 把中国人的饭碗 牢牢端在自己手中” 成为国家共识。主食是我国粮
食转化的主要渠道, 传统主食制造产业是粮食产品 的最佳市场, 成为粮食产业的重要支柱。发达国家 加工食品约占饮食消费总值的 $90 \%$, 而我国的这一 比重仅为 $25 \%$ [1], 这说明我国以粮食为原料的主 食深加工行业发展空间极大。发展传统主食制造产 业对于保障国家粮食安全、推动粮食产业转型升级、 带动粮食产业快速发展具有重大意义。

\section{（二）创新升级传统主食制造产业，满足健康中国 时代背景下消费新需求}

“五谷者，万民之命，国之重宝”，科学食用主 食对百姓健康影响很大。得益于食品产业的发展, 我国居民食品消费已从 “食饱” 过渡至 “食好”, 并正在向 “营养” 逐步迈进。2016 年《“健康中国 2030” 规划纲要》提出 “推进健康中国建设, 提高 人民健康水平”。《中国居民噗食指南 (2016)》建议, 每日全谷物 (包括杂豆类) 摄入量为 $50 \sim 150 \mathrm{~g}$ 。目 前, 消费者对主食制品的营养化、功能化提出了更 高诉求, 使得健康营养的全谷物食品、功能性主食 产品的市场空间扩大。创新升级传统主食制造产业、 构建营养健康多元化的主食制造与消费新生态，是 实现 “健康中国 2030” 战略规划目标的关键内容。

\section{（三）传统主食制造产业助力“一带一路”建设, 弘扬中国传统饮食文化}

从苏轼诗句中 “小饼如嚼月，中有酥与饴” 的 风雅小饼, 到《红楼梦》中有滋补功效的 “糖蒸酥 酪”, 直至现代生活中品种繁多的米面、玉米、杂粮、 薯类，无不承载着我国传统主食文化。“新丝绸之 路经济带” “21 世纪海上丝绸之路” 构成的 “一带 一路” 倡议, 注重积极发展与沿线国家的经济合作 伙伴关系，从而赋予了我国传统主食制造业的新发 展空间 [2]。“一带一路” 沿线既有主食产品丰富的 国家, 也有主食产品匮乏的地区，具有较强的贸易 互补性。推动 “一带一路” 愿景的实现，对于促进 我国主食制造产业 “走出去”、传承和弘扬中国传 统饮食文化具有积极意义。

\section{三、传统主食制造产业发展现状}

（一）传统主食制造原料供应充足, 产量稳步增长 主食的制造和加工离不开原料, 尤其是稻谷、 
小麦、玉米、杂粮和薯类等。稻谷、小麦、玉米作 为我国的三大谷物主食原料, 近 20 年来的产量整 体上呈稳步增长态势（见图 1)，2018 年约占全国 粮食总产量的 $93 \%$ 。

以稻谷为原料生产的大米及其制品是我国居民 最主要的口粮, 稻谷产量总体呈现稳步增长的趋势, 自 2011 年以来年产量均达到 $2.0 \times 10^{8} \mathrm{t}$, 占我国粮 食总产量的比重超过 30\% [3]。

小麦是我国传统面制品主食的主要制造原料, 近 5 年我国小麦年平均总产量约为 $1.3 \times 10^{8} \mathrm{t}$, 馒头、 面条等传统面制品消耗了小麦总产量的 75\% [4]。 我国有约 $90 \%$ 的小麦加工成面粉, 但工业化面制 品加工所用面粉仅占其中的 $25.5 \%$ ：加工成方便面 的面粉占比为 $8 \%$, 加工成挂面的面粉占比为 $4.5 \%$, 用于速冻食品生产的面粉占比为 $6 \%$, 用于面包、 饼干和糕点等焙烤制品生产的面粉占比为 7\% [5]。 因此，我国传统面制品制造原料供应充足、产量稳 步增长, 但工业化生产所占比重较低。

玉米作为另外一种主要的谷物主食原料, 年产 量的增长趋势最为明显, 由 1998 年的 $1.3 \times 10^{8} \mathrm{t}$ 增 加到了 2018 年的 $2.6 \times 10^{8} \mathrm{t}$ 。目前玉米占我国粮食 总产量的 $40 \%$, 产量份额跃居第一位。

我国杂粮品种非常丰富, 主要有高粱、谷子、
荞麦、燕麦、糜子、㯟子、薏仁等谷物杂粮, 菜 豆、绿豆、红小豆、虫豆、踠豆、小扁豆等豆类杂 粮, 甘薯、马铃薯、山药、芋类等薯类。近 20 年, 豆类和薯类产量处于平稳状态， 2018 年豆类产量为 $1.9 \times 10^{7} \mathrm{t}$, 薯类产量为 $2.9 \times 10^{7} \mathrm{t}$ 。

值得指出的是, 马铃薯目前是世界第四大粮 食作物, 成为主食原料的趋势明显。我国马铃薯 产量自 1993 年起一直位居世界首位, 相应产量从 2008 年的 $1.4 \times 10^{7} \mathrm{t}$ 提高到 2018 年的 $1.8 \times 10^{7} \mathrm{t}$ (见 图 2)。2015 年, 国家启动了马铃薯主粮化战略, 采取将马铃薯制作成为米粉、馒头、面条等传统主 食的方式来加快马铃薯主食化的进程 [6]。

\section{（二）主食制造产业已形成较大的市场规模，产业 集聚趋势明显}

近年来，主食加工企业规模呈现持续增长态 势, 经济效益稳步提升。2012 年农村工作主管部 门启动实施了 “主食加工业提升行动”, 在部分省 市先行试点, 组织开展示范企业认定、“科企” 对 接、产品设备展示推介等活动。到 2017 年, 完成 了 5 批 “全国主食加工业示范企业” 认定工作，共 有 336 家企业获得认定, 起到了加快主体培育和示 范引领带动的作用。

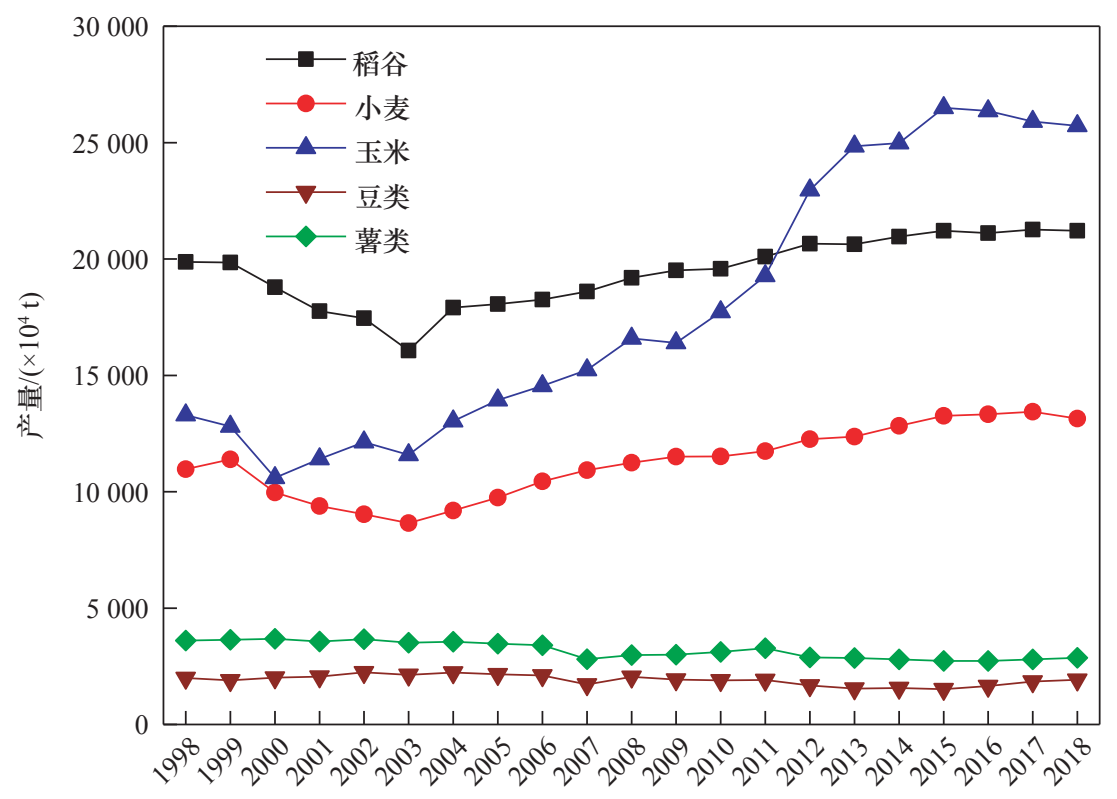

时间/年

图 1 我国传统主食制造原料产量变化情况

注: 数据来源于《中国统计年鉴》（2003-2019 年）。 
主食加工企业数量和主营业务收入均呈现逐年 增长的趋势, 其中以米、面制品企业的发展最为迅 速。米、面制品及食用油法人企业数量增幅较大, 由 2008 年的 905 家增加至 2018 年的 1878 家; 相 关主营业务收入由 2008 年的 1361.0 亿元增加至 2018 年的 6392.2 亿元（见图 3)。主食制造产业市 场规模的逐步扩大, 为整个主食制造产业提供了更 为广阔的市场空间。
在国家政策的引导下，各省市积极培育主食制 造产业集群。目前, 主食加工企业逐步向主食原料 主产区、初加工集中区和主食销售区集聚，产业布 局趋于合理。米制品加工业已基本形成以长江中下 游、东北地区为中心的产业带, 相关企业围绕产业 带分布并以江西省为主要区域。根据不同地区的主 食原料资源优势, 面制品加工业形成了多个主食制 造产业集群。例如, 河南省作为小麦主产区, 分别

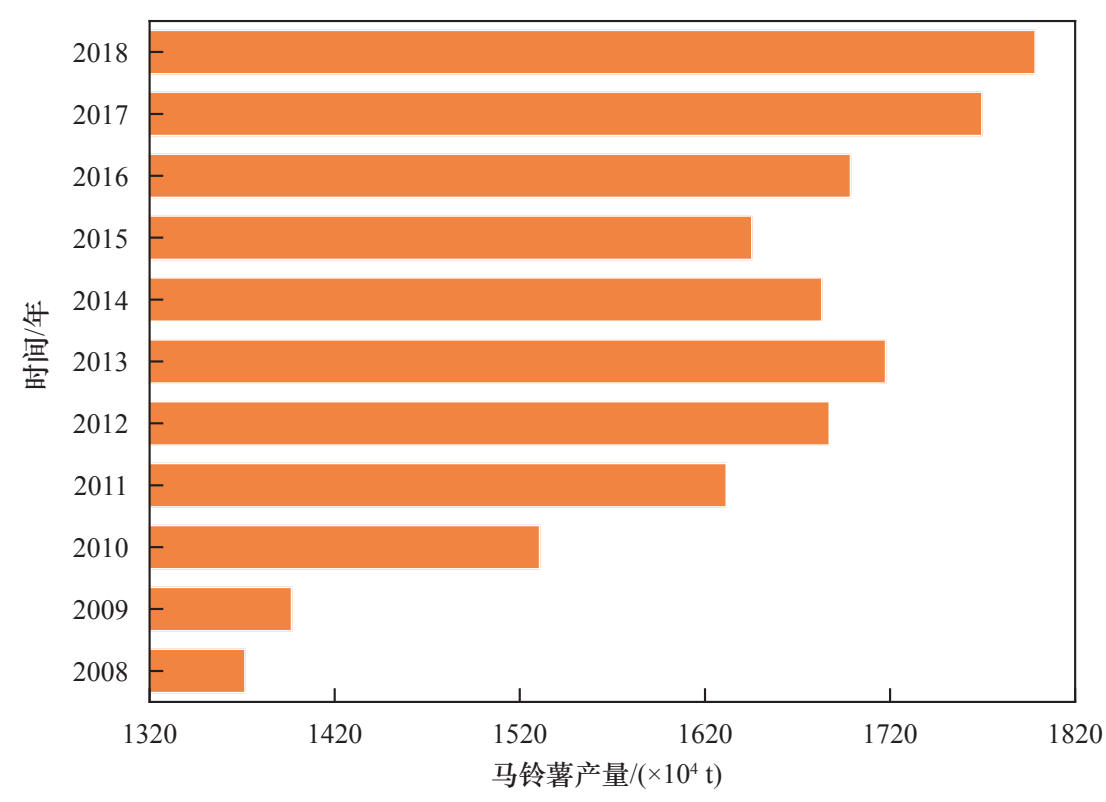

图 2 我国马铃薯产量变化情况（2008-2018 年） 注：数据来源于国家统计局 2008-2018 年度数据。

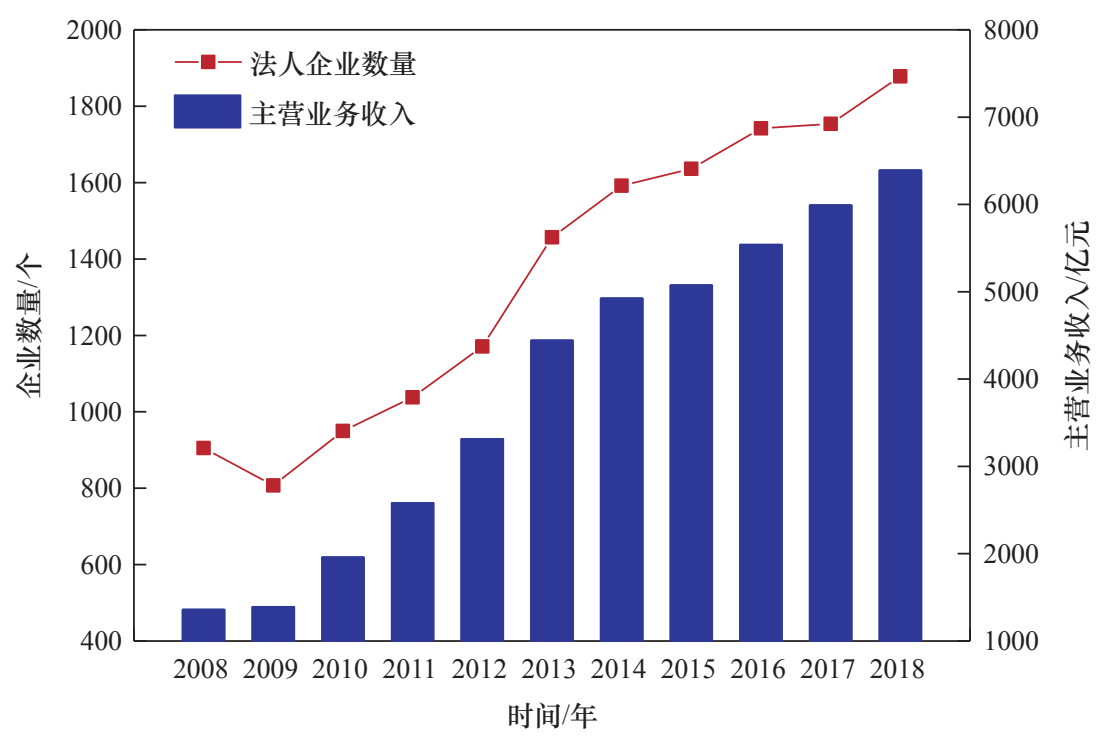

图 3 我国米、面制品及食用油法人企业数量及其主营业务收入变化情况（2008一-2018 年） 注: 数据来源于国家统计局 2008-2018 年度数据。 
在豫北区、豫中区和豫南区打造强筋类、中筋类和 弱筋类面制主食产业化集群, 形成了区域特色, 也 为其他主食制造产业起到了发展借鉴作用。

\section{（三）传统主食制造产业科技支撑体系基本形成}

粮油加工学科是食品科学技术学科的重要分 支, 我国主食制造产业的科技创新发展离不开食品 科学技术学科尤其是粮油加工学科的建设。目前, 设置了粮食工程本科专业的高等院校共有 17 所, 具有食品科学与工程硕士学位授权的高等院校和科 研院所有近 100 所, 具有博士学位授权的有 37 所, 研究方向大部分涉及粮油加工学科。设有食品科学 与工程专业、开设与粮油加工相关课程的高等院校 超过 300 所。这些教育和科研机构为主食制造产业 的科技创新发展提供了基础保障, 为主食制造产业 培养了高水平的从业人员。

国家在传统主食基础科研和应用科研方向保持 了较大的支持力度。“十三五” 时期, 科学技术部立 项的与主食加工相关的国家重点研发计划项目达到 10 项（见表 1)，在大宗米制品、大宗面制品、杂粮 制品、薯类主食设立的 4 个项目总经费达 1.15 亿元。 国家自然科学基金的食品学科设置了 3 个主食 加工领域的申请代码 “C200102 粮油食品原料” “C200504 粮油食品” “C200601粮食、油脂及制品 储藏”, 近年来在这些类别下批准的项目超过 100 项。

在国家级科研项目的技术支持下，传统主食 制造产业突破了多项主食生产及其精深加工关键技 术。在传统米制品方面, 研制了留胚米低压磨削碾 白技术与装备, 创建了䊁米蒸煮及食用品质改良技
术，在多家企业实现产业化应用。在传统面制品方 面，大幅提升了制面、干燥和包装设备的自动化与 智能化水平，智能化仿生馒头生产线投产应用。在 传统玉米制品加工方面, 攻克了微波辅助生物修饰、 质构重组、老化控制等玉米饺子和玉米馒头生产关 键技术，突破了玉米重组米生产关键技术，建成了 玉米精深加工食品生产线。在传统杂粮制品方面, 研制了杂粮蒸煮及食用品质改良技术、燕麦灭酶技 术与装备、燕麦全粉加工技术与装备，创制了杂粮 主食制品系列生产线。在马铃薯主食方面, 突破了 马铃薯薯泥、薯浆、米制品类、面条类产品的加工 关键技术，创建了马铃薯中式主食系列生产线。

\section{四、传统主食制造产业面临的问题}

\section{（一）加工适宜性良好的专用品种结构单一}

传统主食制造的原料品种比较多，在主食制造 过程中容易出现加工工艺因原料品种、年份、产地 不同各异, 加工过程及产品品质控制难度较大, 实 用技术难以复制推广, 产品质量的稳定性因无法有 效量化而难以保障等现象, 直接导致传统主食制品 市场竞争力不强、经济效益低下等问题。

稻谷、小麦、玉米等粮食作物有临时收储政策, 但临时收储不分品种优劣, 使得农户趋向于种植有 临时收储政策的粮食品种, 致使传统主食制造原料 的品种结构单一化、低品质化趋势越发明显。因此, 将选种、育种与主食加工有效关联, 推广种植传统 主食加工适宜性良好的专用品种是当前面临的一大 问题。

表 1 “十三五” 时期主食加工方向的国家重点研发计划项目情况

\begin{tabular}{ll}
\hline 立项时间/年 & \multicolumn{1}{c}{ 项目名称 } \\
\hline 2016 & 薯类主食化加工关键新技术装备研发及示范 \\
2016 & 方便即食食品制造关键技术开发研究及新产品创制 \\
2016 & 中华传统食品工业化加工关键技术研究与装备开发 \\
2017 & 大宗米制品适度加工关键技术装备研发及示范 \\
2017 & 传统杂粮加工关键新技术装备研究及示范 \\
2017 & 食品风味特征与品质形成机理及加工适用性研究 \\
2018 & 大宗面制品适度加工关键技术装备研发与示范 \\
2018 & 民族特色工业化食品加工关键技术与装备开发 \\
2018 & 野外自热食品品质提升与制造关键技术研究 \\
2018 & 预制调理食品制造关键技术与新产品研究及新型速冻技术装备开发 \\
\hline
\end{tabular}




\section{（二）主食制品深加工水平低, 产品结构不合理}

整体来看, 虽然主食制造产业发展势头良好, 但依然存在深加工水平较低、初级产品产出较多、 产品同质化严重、加工企业小而分散等问题; 市场 上能够满足改善膳食需求和营养需求的相关产品较 少, 且大多缺乏标准规范和技术规程。

在主食制造产业中, 精细加工的谷物主食比 重较大, 而各类营养主食如全谷物食品的比重很 低; 普通低档主食产品多, 中高档产品少。例如 在米制主食产品加工领域, 米粉、汤圆、粽子 等普通主食所占比重较大, 营养早餐谷物食品、 功能性米粉等精深加工主食制品的市场份额较 小 [8]。这一局面制约了主食制造产业的提质增效 和转型升级。

\section{（三）传统主食多样化和营养化发展水平低}

我国居民食品消费正处于由 “食好” 阶段向 “营 养” 阶段的过渡时期, 主食消费品种趋于多样化和 营养化。我国传统主食仅有 300 多个品种, 而国外 意大利通心面多达 800 个品种, 汉堡包有 100 多个 品种 [7]。

传统主食缺乏多样性, 导致居民谷物摄入量明 显下降, 动物性食物摄入明显升高。主食提供的碳 水化合物、膳食纤维、B 族维生素等食物营养素缺 乏, 营养搭配较少, 容易引起肥胖、心血管疾病等, 不利于国民健康。为了顺应我国从生存型消费向营 养型消费的转变, 丰富主食品种, 开发杂粮、全谷 物食品主食产品, 加强主食营养化, 这些都是亟待 解决的问题。

\section{（四）高新技术与智能专用装备的应用比例较低}

我国传统主食历史悠久, 长期以来主要是以传 统小作坊的形式, 凭借经验和传统方法开展生产。 研究相对滞后成为加工技术落后的根本原因, 亟 需采用现代科技手段予以改良。发达国家已经普 遍实现了超高压、真空和面、波纹辊压延等高新 技术在主食加工业中的应用, 我国在这方面存在 一定的差距。

我国主食加工装备工业起步较晚, 普遍维持 粗加工模式, 缺少专业化配套装备; 主食制造企 业装备自主研发能力较弱, 缺乏核心技术与市场 竞争力。随着传统主食制造产业规模化程度的提
高、社会劳动力成本的不断增加, 自主研发适合 我国传统主食加工工业化和标准化生产的智能专 用装备, 已成为主食产业实现智能制造发展的迫 切需求。

\section{（五）主食制品标准化体系有待进一步完善}

国家主管部门制定的《小麦粉馒头》《馒头用 小麦粉》《面包用小麦粉》等一批国家标准和行业 标准, 在促进我国传统主食制造产业的标准化发展 方面发挥了积极作用。然而, 传统主食本身衍生 种类繁多, 很多主食产品没有统一的产品标准体 系, 无法真正突破地域限制, 相应的工业化和标 准化发展受到制约。与发达国家相比, 我国主食 加工的现行标准水平较为低下, 标准体系不健全、 不完善, 尤其是健康谷物及主食标准体系建设明 显滞后。

\section{五、对策建议}

\section{（一）抓牢源头, 选育适宜传统主食加工的优质专 用品种}

从主食加工和居民营养的角度对育种界提出要 求, 抓牢品种繁育、种植基地等重点工作; 依托品 种加工适宜性评价体系, 对主食加工的原料品种 进行选育或改良。例如, 针对不同加工需求, 选 育出油炸专用型、淀粉专用型等马铃薯品种; 从 营养的角度出发, 重点选育富锌、富硒的稻米品 种, 生产出功能性主食制品。着力推广这些优质 专用主食品种, 进一步丰富我国传统主食制造原 料种植品种。

\section{（二）调整产品结构, 推进传统主食制造产业改造 升级}

倡导米、面的适度加工, 最大限度地保持米、 面原有的营养物质。积极开发以特色米、面, 功能 性米、面为原料的功能性米粉、营养早餐谷物食品 等营养健康米制、面制主食产品。推进玉米、杂粮 及薯类主食制品的工业化生产, 以丰富市场供应、 满足人群的差异性需求。延伸主食制造产业链条, 提高副产物综合利用率。开发具有高附加值的精深 加工制品, 优化传统主食制造产品结构, 促进主食 制造产业的高质量和可持续发展。 


\section{（三）发展全谷物食品, 推动向健康谷物与健康主 食以及精准营养的创新升级}

《国民营养计划（2017-2030 年)》开启了 “健 康中国、营养先行” 的全民营养时代。为了匹配增 加全谷物摄入的发展目标, 建议加强全谷物食品的 科学研究, 实施配套的科普宣传, 推动传统主食加 工向健康谷物与健康主食的创新升级。进一步挖掘 全谷物食品中的营养因子，根据不同目标人群开发 个性化的精准营养方案, 保障国民营养健康的需求。

\section{（四）加强技术与装备研发，支持传统主食制造产 业与智能制造深度融合}

加大传统主食制品基础理论和应用研究的科研 投入，以科技创新驱动主食制造产业的长远发展。 加强传统主食制造关键技术装备的开发, 突出智能 化、绿色环保、节能减排、节粮减损的技术导向。 融入主食芯片增材制造、智能醒发、自动化包装等 高新智能技术，研制适合国情的工业化、规模化、 连续化生产线，支持传统主食制造产业朝着标准化、 自动化、智能化方向发展。

\section{（五）完善标准体系，促进传统主食制造产业走向 规范化和科学化}

借鉴或引进发达国家主食制造标准体系，研 究分析具体标准和法规内容。结合国家标准体系架 构的调整，发挥主食制造相关的社会团体作用，制 定一批以促进产业发展和技术进步为目标的团体标 准。加强国家标准和行业标准的制定和修订工作, 支持我国相关机构参与国际标准化组织的主食标准 研究，提升我国传统主食制造产业的国际影响力和 竞争力。
参考文献

[1] 国家粮食局. 建设粮食产业强国实践与探索 [M]. 北京: 中国财 富出版社, 2018.

State Administration of Grain. Practice and exploration of constructing: A powerful country in grain industry [M]. Beijing: China Fortune Press, 2018.

[2] 赵予新. “一带一路”框架下中国参与区域粮食合作的机遇与对 策 [J]. 农村经济, 2016 (1): 14-19.

Zhao Y X. Opportunities and countermeasures of China's participation in regional food cooperation under the framework of the Belt and Road [J]. Rural Economy, 2016 (1): 14-19.

[3] 国家统计局. 中国统计年鉴-2019 [M]. 北京: 中国统计出版社, 2019.

National Bureau of Statistics. China statistical yearbook-2019 [M]. Beijing: China Statistics Press, 2019.

[4] 杨铭铎, 芦健萍. 我国几种主食工业化生产技术研究进展 [J]. 粮 食与饲料工业, 2017 (1): 3-9.

Yang M D, Lu J P. Research progress in industrialization production technology of several kinds of Chinese staple food [J]. Cereal \& Feed Industry, 2017 (1): 3-9.

[5] 张兴宇. 面食工业化的现状及发展策略研究 [D]. 太原: 山西农 业大学(硕士学位论文), 2016 .

Zhang X Y. Current situation and development strategy of pasta industrialization [D]. Taiyuan: Shanxi Agricultural University (Master's thesis), 2016.

[6] 杨雅伦, 郭燕枝, 孙君茂. 我国马铃薯产业发展现状及未来展望 [J]. 中国农业科技导报, 2017, 19(1): 29-36.

Yang Y L, Guo Y Z, Sun J M. Present status and future prospect for potato industry in China [J]. Journal of Agricultural Science and Technology, 2017, 19(1): 29-36.

[7] 张泓, 黄峰, 胡宏海. 主食工业化叒待解决的问题 [J]. 农产品加 工, 2014 (5): 18-19.

Zhang $\mathrm{H}$, Huang F, Hu H H. Burning questions in staple food industrialization [J]. Farm Products Processing, 2014 (5): 18-19.

[8] 吴立根, 王岸娜, 屈凌波. 我国产业化主食的发展与瓶颈 [J]. 粮 食与饲料工业, 2016 (1): 1-4.

Wu L G, Wang A N, Qu L B. Development and bottleneck problem of staple food industrialization in China $[\mathrm{J}]$. Cereal \& Feed Industry, 2016 (1):1-4. 